\title{
NOTE ON LUMBAR PUNCTURE WITH THE DATTNER PATTERN OF NEEDLE
}

\author{
By L. W. HARRISON
}

In their paper on the Treatment and Prophylaxis of Neurosyphilis which is published elsewhere in this number of the JOURNAL, Nicol and Hutton have spoken well of a double needle for lumbar puncture which I have helped to make known in this country. I agree that with the use of this needle the bugbear of headache following lumbar puncture is largely eliminated, and the following note on lumbar puncture with it may therefore be of interest.

The instrument is on the principle first advocated by Hoyt of puncturing the skin and ligaments with a needle which is stout enough to take the strain of overcoming the resistance of these moderately tough tissues but puncturing the dura and arachnoid with a much finer needle carried inside the stouter one, beyond the point of which it can be projected when required. The Dattner pattern was first brought to my notice by Messrs. Down Bros. a few years ago when I was experimenting with a very fine needle in the hope of preventing lumbar puncture headache by obviating leakage of fluid through the puncture wound in the membranes. Previously I had tried a needle of the Hoyt pattern bought in America in I929, but had discarded it because the inner needle was only slightly thinner than the single needle which I had previously used (2I SWG as compared with I9) and did not project far enough (only a quarter of an inch) beyond the outer needle to make it easy to avoid puncturing the membranes with this also. As the gauge of the outer needle was $I 7$, the risk of leakage would be much greater if the outer needle punctured the membrane than if one were to use a single needle of gauge I9. Dattner's account of the pedigree of this needle is that Hoyt first advocated the use of a double needle in lumbar puncture, but the first account of its use on any large scale was by Antoni, Stockholm, in I923, and Wechselmann, followed by Mulzer and then Dattner, modified it chiefly in respect of its grip. The pattern made for me by Messrs. 


\section{BRITISH JOURNAL OF VENEREAL DISEASES}

Down Bros. is shown in Figs. I and 2. It differs from the Dattner needle in only a few small details. One is that the instrument is introduced with the inner needle already in position, its point flush with that of the outer needle, ready to be pushed forward as shown in Fig. 2 as soon as the operator judges that he has reached the dura. Another difference is that the base of the inner needle on which the fixation screw shown in the illustration impinges is stronger and flattened, so that when the inner needle is withdrawn to the position shown in Fig. I, a stop catches on the point of the fixation screw when the point of the inner needle is flush with that of the outer one. The inner needle can be projected half an inch beyond the point of the outer one, so that there is a reasonably large margin of safety from the danger of puncturing the membranes

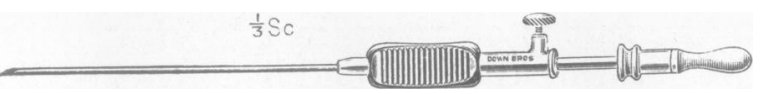

FIG. I.-Dattner lumbar puncture needle ready for introduction, with inner member retracted.

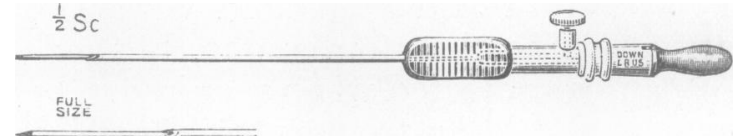

FIG. 2.-Dattner lumbar puncture needle with inner member projected.

with the outer needle. The gauge of the inner needle is $24(0.5 \mathrm{~mm}$.) or slightly less than that of an ordinary pin, which is 22. The gauge of the outer needle is $20(0.9 \mathrm{~mm}$.), or approximately the same as White's modification of Jeanselme's, and of the pattern sometimes known as the Rochester Row which I formerly used, so that if by chance the membranes are punctured with the outer needle, the patient is no worse off than if a needle of the older pattern had been used.

$\mathrm{H}$. W. Allen, who first reported on the use of this needle in England, showed that II6 punctures in which only the inner needle penetrated the spinal canal were followed by only two headaches of such severity as to make the patient lie up, while in 16 others there had been slight headache. On the other hand, II punctures in which the membranes had been punctured by the outer needle also had been followed by severe headache in 5 cases. My own experience, like that of Allen and of Nicol and Hutton, is 


\section{LUMBAR PUNCTURE}

that, provided care is taken to avoid pusining the outer needle through the arachnoid, lumbar puncture with this needle is followed by such a low percentage of headache as to justify its performance on out-patients. The following further notes may perhaps help some readers to carry out lumbar punctures with this needle with a minimum of discomfort for the patient.

I prefer the sitting position, and tell the patient to drop his hands between his thighs, letting his head and shoulders sag forward, very much as is shown in Fig. 3. A

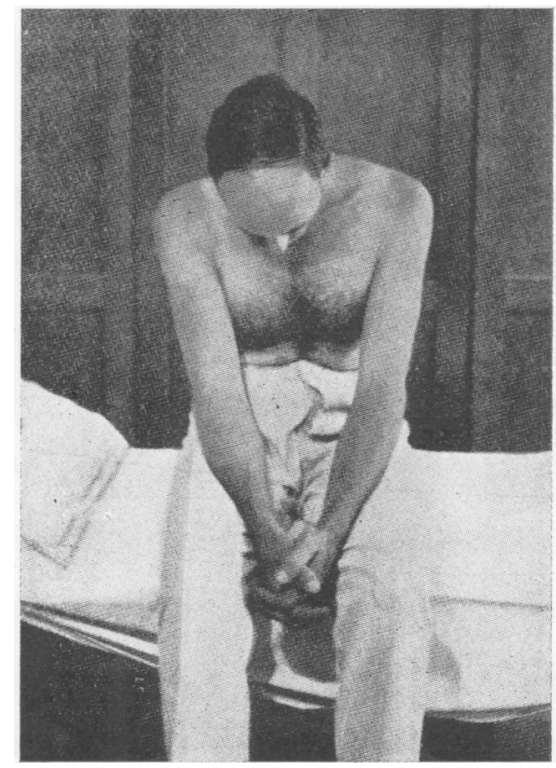

FIG. 3.-Convenient position of patient for lumbar puncture. (Reproduced by kind permission from Dattner's "Moderne Therapie der Neurosyphilis."

convenient method of finding the interspace of choice is to hold a piece of irrigator tubing against the patient's back so that it half encircles it with the tubing touching the highest points of the iliac crests. If it intersects bone, I choose the space above. It is a good thing to mark carefully with a skin pencil on either side of the spot in the interspace into which one can most easily press the end of a thumb. A local anæsthetic is well worth while, especially with a nervous patient, who is not then so likely to worry if the canal is not found at the first attempt. I have found infiltration with procaine by means of the 


\section{BRITISH JOURNAL OF VENEREAL DISEASES}

Waite's cartridge type syringe most convenient; it is sold by the Amalgamated Dental Company. Without any preliminary wheal being made, the needle, which is hair-like, is pushed along the track to be followed by the lumbar puncture needle, but need not go deeper than about $\mathrm{I} \frac{1}{2}$ inches. In the insertion of the needle the strongest concentration on the aim pays well. I enter the needle in the middle line behind and aim as if to make it come out in the middle line in front, consciously correcting my invariable tendency to direct it towards the left.

The point of the lumbar puncture needle should be examined with a hand lens before use to see that the bevel is perfectly smooth; it should always be sharpened when assembled as for introduction through the skin. It seems to be an advantage to hold the lumbar puncture needle so that when it punctures the membranes its bevel will be directed towards the patient's side. In using the needle at first, the tendency may be to push it in too far before loosening the screw and pressing forward the inner member, with the result that the membranes are punctured by the outer needle, and the whole purpose of the design is lost. As a rule, it is best to stop and push on the inner needle when about half the instrument has been buried. After pushing on the inner needle and withdrawing the stilette, the operator should wait and watch the base of the needle closely for a few seconds, perhaps rotating it and even applying suction with a record syringe, before concluding that the point has not entered the spinal canal. If fluid does not come, the inner needle is pulled back and the instrument is pushed on another quarter of an inch before trying again. When fluid begins to appear I help it out very slowly by applying suction with a record syringe. When the required amount of fluid has been withdrawn I remove the inner needle completely so as to verify, by the absence then of any flow, that the outer needle has not punctured the arachnoid. After the operation the patient is made to lie prone for about twenty minutes before dressing and going home.

\section{BIBLIOGRAPHY}

Allen, H. W. : " Headache following Lumbar Puncture," B.M.J., I934, ii, 349.

DAtTNER, B.: “Moderne Therapie der Neurosyphilis mit Einschluss der Punktionstechnik und Liquoruntersuchung," Wien. W. Maudrich, I933, pp. 6-Io. 